\section{A NEW MONOGRAPH ON DDT} DDT

Das Insektizid Dichlordiphenyltrichloräthan und Seine Bedeutung. Herausgegeben von Paul Müller. Vol. 1. (Lehrbücher und Monographien aus dem Gebiete der Exakten Wissenschaften. Chemische Reihe-Band 9.) Pp. 300. (Basel und Stuttgart: Birkhäuser Verlag, 1955.) 37.50 Swiss francs; 37.50 D. marks.

$\mathrm{T}$ HE insecticide DDT has been well known for a dozen years, though latterly a number of new synthetic compounds have emerged to challenge its superiority in various fields. However, there are not so many new types of insecticide as may appear from the lists of names; most of the newcomers belong either to the chlorinated terpene group (to which $\gamma$-benzene hexachloride is toxocologically allied) or to the phosphoric acid series. The discovery of a now class of insecticides is, in fact, rare. DDT marked such an advance that it is generally considered to have opened a new era of pest control, and it continues to be widely and satisfactorily used for many purposes.

A fow years ago Dr. P. Müller, of Geigy, who was largely concerned with its discovery, decided that the time was ripe for a new monograph on DDT. The first volume has now appeared, in the form of a symposium of five sections, by Swiss, British, Austrian and Swedish authors. Four of the contributions are in German and one in English, with summaries in the alternative language. One or two books on DDT have already been published, though none recently. About the best was that by $T$. F. West and G. A. Campbell (1950); but these authors admitted delays in publication, and their text contains no reference later than 1946. (To remedy the defect, they added a supplement of more than eight hundred references for 1947 and 1948, which gives some idea of the enormous output of papers on the subject.)

The present monograph takes the account up to 1953 ; but the more recent work has added very little to the data on physical and chemical matters that comprise Section 1, by Dr. Müller himself. Section 2, by Prof. V. B. Wigglesworth, summarizes our knowledge on the mode of action of DDT, this contribution being by far the most generally interesting. It begins by considering factors involved in the contamination of insects by DDT and continues to the final minutæ of intoxication--so far as they are known. This lucid survey integrates the findings of 137 papers, 80 per cent of them published between 1946 and 1951. After reading it, we still do not know how DDT kills ; but the possibilities are greatly narrowed.

The remaining contributions are of a more practical nature and deal with the use of DDT against particular types of pests. Section 3, by Dr. E. Bernfus, of Vienna, deals with the control of stored product pests, especially those of breweries. In view of the serious importance of toxic residues, methods are described for determination of DDT traces in food. Section 4, by Dr. O. Walchli, of St. Gallen, Austria, discusses the use of DDT for protecting woollen textiles against clothes moths and carpet beetles. The final section, on control of forest insect pests, is by Dr. V. Butovitsch, of Stockholm. It gives full details of spraying and dusting by aircraft and from the ground against the woodland pests.
No information on control of agricultural and horticultural pests is given in this volume, nor are insect disease vectors or parasites mentioned; no doubt they will receive attention in the next volume. J. R. BUSviNe

\section{GEOPHYSICAL RESEARCH IN NORTH AMERICA}

Advances in Geophysics

Edited by H. E. Landsberg. Vol. 2. Pp. $x+286$. (New York : Academic Press, Inc.; London: Academic Books, Ltd., 1955.) 7.50 dollars.

HIS volume is the second in a series. It contains five essay reviews, each approximately fifty pages in length, dealing with recent advances in various branches of geophysics. Each is by a separate author or authors; but the whole volume is edited by H. E. Landsberg, of the United States Weather Bureau, assisted by a small advisory committee. As might be expected of a composite work of this kind, the style and quality of the different contributions vary considerably; but, on the whole, a high standard is maintained. Each essay contains a good bibliography, and author and subject indexes are provided.

In the first essay, on advances in radar weather, J. S. Marshall, W. Hitschfeld and K. L. S. Gunn (McGill University) describe typical precipitation patterns and give an outline of the ways in which quantitative data can be derived from radar signals. In "Methods of Objective Weather Forecasting", by I. I. Gringorten (Air Force Cambridge Research Center, Cambridge, Mass.), various objective methods of weather forecasting are classified, and the success and future objective of such systems discussed. W. J. Pierson, jun. (Department of Meteorology and Oceanography, New York University), discusses windgenerated gravity waves, and gives an outline of mathematical methods of describing such waves. This can be applied to analyse the form and motion of actual waves at sea. Some practical methods of observing and forecasting are also considered. In the essay on geological chronometry by radioactive methods, J. L. Kulp (Lamont Geological Observatory, Columbia University, New York) gives brief accounts of the lead, carbon-14, strontium, potassium, helium and ionium methods of radioactive dating and also reviews some other potential methods. The final essay is on earthquake seismographs and associated instruments, by H. Benioff (Department of Seismology, California Institute of Technology). The progress in design during the past twenty-five years is illustrated by short descriptions of some thirty different types of seismograph; advances in methods of recording and time-keeping are also summarized.

The whole volume is written and produced in North America. It is not surprising, therefore, to find that most of the work described has been carried out either in the United States or Canada. Within this field, the reviews are fairly complete; but they could be improved if research carried out in other countries were more fully treated. As a series of reviews of recent geophysical work in North America, this book can be strongly recommended, and future volumes in the series will be awaited with interest.

B. C. Browne 